\title{
Lack of Cross-resistance Between Non-steroidal and Steroidal Aromatase Inhibitors in Breast Cancer Patients: The Potential Role of the Adipokine Leptin.
}

\section{Nazli Bahrami}

Akershus Universitetssykehus HF

Shakila Jabeen

Akershus Universitetssykehus HF

\section{Torill Sauer}

Universitetet i Oslo

\section{Hilde Presterud Ødegård}

Akershus Universitetssykehus HF

\section{Stephanie Beate Geisler}

Akershus Universitetssykehus HF

\section{Berit Gravdehaug}

Akershus Universitetssykehus HF

\section{Laurens Cornelus Reitsma}

Akershus Universitetssykehus HF

Knut Selsås

Akershus Universitetssykehus HF

Vessela Kristensen

Oslo Universitetssykehus

Jürgen Geisler ( $\nabla$ juergen.geisler@medisin.uio.no )

Akershus Universitetssykehus HF https://orcid.org/0000-0001-6239-3856

Research article

Keywords: breast cancer, aromatase inhibitor, letrozole, exemestane, adipokine, leptin

Posted Date: August 21st, 2020

DOI: https://doi.org/10.21203/rs.3.rs-62421/v1

License: (a) (i) This work is licensed under a Creative Commons Attribution 4.0 International License.

Read Full License 
Version of Record: A version of this preprint was published at Breast Cancer Research and Treatment on September 23rd, 2021. See the published version at https://doi.org/10.1007/s10549-021-06399-x. 


\section{Lack of cross-resistance between non-steroidal and steroidal aromatase inhibitors in breast cancer patients: the potential role of the adipokine leptin}

Nazli Bahrami ${ }^{1,2}$, Shakila Jabeen ${ }^{3,5}$, Torill Sauer ${ }^{4,5}$, Hilde Presterud Ødegård ${ }^{1}$, Stephanie Beate Geisler ${ }^{1}$, Berit Gravdehaug ${ }^{2}$, Laurens Cornelus Reitsma ${ }^{2}$, Knut Selsås², Vessela Kristensen ${ }^{3,5}$, Jürgen Geisler ${ }^{1,6 *}$

Departments of Oncology ${ }^{1} \&$ Breast and Endocrine Surgery ${ }^{2}$, Clinical Molecular Biology $(\text { EpiGen })^{3}$, and Pathology ${ }^{4}$ at Akershus University Hospital, Lørenskog, Norway, Department of Cancer Genetics, Institute for Cancer Research, Oslo University Hospital ${ }^{5} \&$ Institute of $^{2}$ Clinical Medicine ${ }^{6}$, University of Oslo, Oslo, Norway.

*Correspondence: Professor Jürgen Geisler, MD, PhD, Institute of Clinical Medicine, University of Oslo, Norway \& Akershus University Hospital, Department of Oncology, Lørenskog, Norway; juergen.geisler@medisin.uio.no; Cell phone (+47) 91187447; 


\section{Abstract}

Background: The aromatase inactivator exemestane may cause clinical disease stabilization following progression on non-steroidal aromatase inhibitors like letrozole in patients with metastatic breast cancer, indicating that additional therapeutic effects, not necessarily related to estrogen-suppression, may be involved in this well-known "lack of cross-resistance".

Experimental design: Postmenopausal women with ER positive, HER-2 negative, locally advanced breast cancer were enrolled in the NEOLETEXE-trial and randomized to sequential treatment starting with either letrozole (2.5 mg o.d.) or exemestane (25 mg o.d.) followed by the alternative aromatase inhibitor. Serum levels of 54 cytokines, including 12 adipokines were assessed using the Luminex xMAP technology (multiple ELISA).

Results: Serum levels of leptin were significantly decreased during treatment with exemestane $(\mathrm{p}<0.001)$, regardless whether exemestane was given as first or second neoadjuvant therapy. In contrast, letrozole caused a non-significant increase in serum leptin levels in vivo.

Conclusions: Our findings suggest an additional and direct effect of exemestane on CYP-19 (aromatase) synthesis presumably due to effects on the CYP19 promoter use that is not present during therapy with non-steroidal aromatase inhibitors. Our findings provide a reasonable explanation for the clinically observed lack of cross-resistance between nonsteroidal and steroidal aromatase inhibitors in breast cancer patients.

Keywords: breast cancer, aromatase inhibitor, letrozole, exemestane, adipokine, leptin;

Trial registration: registered on March $23^{\text {rd. }} 2015$ in the National trial database of Norway (Registration number: REK-SØ-84-2015). 


\section{Background}

The third-generation aromatase inhibitors (AIs) (anastrozole, letrozole and exemestane) are currently widely used to treat estrogen receptor positive $(\mathrm{ER}+)$ breast cancer in postmenopausal patients in all stages of the disease [1-6].

Anastrozole and letrozole belong to the class of (type-I) non-steroidal aromatase inhibitors binding competitively to the P450 part of the aromatase enzyme. In contrast, the steroidal (type-II) aromatase inactivator exemestane binds irreversibly to the substrate binding pocket (active site) of the aromatase enzyme [7-9]. The fundamental biochemical differences between non-steroidal and steroidal aromatase inhibitors are of particular interest as a "lack of cross-resistance" has been documented by several clinical trials [10-16], providing the rationale for the use of exemestane following disease progression with a nonsteroidal compound [17]. However, the precise explanation for the observed lack of cross-resistance between steroidal and nonsteroidal aromatase inhibitors is still unknown and it has been suggested that a detailed understanding of this clinical phenomenon may potentially provide a new strategy to treat hormone-sensitive breast cancer $[18,19]$. To investigate the fundamental differences in the effects caused by non-steroidal AIs and steroidal AIs in vivo, we designed the NEOLETEXE-trial [20]; (Figure 1). The present manuscript reports the results of a planned cytokine-substudy of the NEOLETEXE-trial.

Adipose inflammation is increasingly recognized as a crucial factor in breast cancer carcinogenesis and progression [21, 22]. Typical consequences are hyperinsulinemia, elevated insulin-like growth factor I (IGF-I) levels, adipokine imbalances including leptin elevation as well as increased estrogen levels [21]. The adipokine leptin seems to play a pivotal role through binding to specific membrane receptors and inducing different signaling pathways, including the JAK/STAT, MAPK, IRS 1 and $\mathrm{SOC}_{3}$ pathways [23]. Leptin is also involved in the regulation of body weight and is an important mediator of obesity as it controls food 
intake and energy balance by signals to the hypothalamus [24-26]. An excess of body fat mass increases the breast cancer risk, especially in postmenopausal women where estrogen production by adipose tissue through its own aromatase activity stimulates tumor progression [27]. Leptin is secreted by normal and malignant breast tissue and has been shown to enhance the expression of aromatase via promoter II and I.3 using an AP-1 motif [27]. A significant association between plasma sex hormones and plasma leptin levels has been reported [28, 29] and previous studies have shown that postmenopausal women with breast cancer have higher concentrations of plasma leptin [30,31]. In a previous publication we could also show that plasma leptin levels are tightly correlated to the basic whole body aromatization in postmenopausal women [31].

In this study, we evaluated the serum levels of 54 cytokines, including all 12 known adipokines, relative to given treatment with letrozole and exemestane in a neoadjuvant setting, aiming for a direct head-to-head comparison in vivo. We hypothesized that the different effects of letrozole and exemestane on the expression of crucial adipokines like leptin may play a key role in the mentioned lack of cross-resistance between type-I and type-II aromatase inhibitors. Importantly, our study was not designed to compare the clinical effects on the breast cancer tumors as both drugs have been shown to cause comparable tumor shrinkage in the neoadjuvant setting in previous trials.

\section{Methods}

Trial design and patients

The NEOLETEXE-study (Fig. 1) is a neoadjuvant, randomized, open-label, intra-patient, cross-over trial with the intention to study the effects of sequential aromatase inhibition by type-I aromatase inhibitor letrozole and type-II aromatase inactivator exemestane in a randomized, intra-patient cross-over fashion in vivo. The trial has been approved by the 
Regional Ethics Committee of South-East Norway (project number 2015/84) [20]. In this particular sub-study, a total of 39 postmenopausal women, all diagnosed with locally advanced, ER-positive and HER-2 negative primary cancer were included (Table 1). Locally advanced breast cancer is generally defined as either T3-T4 and/ or N2-3 primary breast cancer. However, patients with tumors above $4 \mathrm{~cm}$ but below $5 \mathrm{~cm}$ in diameter ("large T2tumors") were also includable in accordance with the international trend to provide neoadjuvant therapies to these patients in clinical trials. We defined postmenopausal status as age above 55 years or age above 50 years and at least 2 years of amenorrhea in addition to LH-, FSH- and plasma estradiol levels in the postmenopausal range.

Patients were randomized to neoadjuvant endocrine therapy by one of two treatment arms (Figure 1):

Treatment arm 1: letrozole $2.5 \mathrm{mg}$ o.d. for at least 8 weeks, followed by exemestane $25 \mathrm{mg}$ o.d. for another 8 weeks prior to surgery.

Treatment arm 2. exemestane $25 \mathrm{mg}$ o.d. for at least 8 weeks, followed by letrozole $2.5 \mathrm{mg}$ o.d. for another 8 weeks prior to surgery.

Collection of blood samples, open tumor biopsies, MRI evaluations and clinical examinations were performed at baseline (before initiation of any therapy), following at least 2 months on the first AI treatment (directly before switching to second treatment) and finally directly prior to surgery. 


\section{Cytokine Multiplex profiling}

In total 54 cytokines including all 12 adipokines, IL10 family cytokines, IL6 and its receptors, IFN, tumor necrosis factor (TNF) superfamily cytokines, growth factors, osteokines and selected matrix metalloproteinases (MMPs) were analyzed in serum samples of 39 postmenopausal breast cancer patients. Blood samples were obtained at three timepoints: at baseline and following at least 2 months and 4 months on therapy with the two individual aromatase inhibitors given in a randomized sequence as monotherapy. The multiplex profiling platform Luminex 200 was used for quantitative analysis of the cytokines. We used three commercially available cytokine panels from Bio-Rad and one panel from Millipore. Panels from Bio-Rad included: 37-plex Pro Human Inflammation Panel 1 (lot\# 64161726), Pro Human Adiponectin 1-plex Panel (lot \#10010747) and 15-plex including 10-plex Pro Diabetes Panel (lot \#64065098) plus five cytokines: IL6, IP10, VEGF, PDGFbeta and TNFalpha (standards lot\# 64103329). The interleukin 24 (IL-24) single plex panel was purchased from Millipore (lot\#HCYP4MMAG-64K-IL-24). Signal intensities of protein concentration for all cytokines were determined in a series of control standard dilutions to create standard curves as instructed by the manufacturers. The total serum protein level for each cytokine was assessed according to their locations on the standard curves using Bio-Plex Manager 6.0 (Bio-Rad). Data was exported to excel sheets for further analysis.

\section{Statistical Analysis}

All analyses were performed after natural $\log$ transformation of the observed data using IBM SPSS Statistics 25 and Excel 2016. Cytokine levels were analyzed in relation to categorical clinical parameters using ANOVA, Mann-Whitney-U (MWU), Kruskal-Wallis and t-tests. Unless otherwise stated, results were considered statistically significant, if the two-sided pvalue was $<0.05$. The cytokine correlation analysis was performed for pretreatment (baseline) 
log-transformed serum levels using Spearman correlations. Visualization of all finding was performed by using either IBM SPSS Statistics 25's graphic elements or by use of Excel 2016.

\section{Results}

We performed a serum level variation analysis for 54 cytokines from samples collected from 39 postmenopausal patients with locally advanced, ER positive, HER-2 negative breast cancer (Table 1). The patients were randomized into one out of two treatment arms receiving neoadjuvant endocrine treatment with either letrozole or exemestane for at least 8 weeks before switching to the other alternative drug for at least another 8 weeks before undergoing final surgery. The treatment plan, drugs and sample collection timepoints are shown in Fig. 1.

Cytokine serum levels were measured using multiplex array system Luminex xMap and observed values were log normalized. Table 2 summarizes the log transformed cytokine levels for all patients and the influence of treatment with letrozole and exemestane, respectively (given as differences to baseline values). Statistical analyses were performed using normalized serum levels values of the cytokines against clinical parameters and observations. Table 2 presents the results of our findings illustrated in groups or families of cytokines which are put together because of their common function, origin, or both. Spearman correlations were calculated between all adipokine baseline values as summarized in Fig. 2 .

Serum levels of leptin were found to be significantly decreased during treatment with exemestane compared to treatment with letrozole $(\mathrm{p}=0.019)$, regardless whether exemestane was given as first or second therapy (Fig. 3). Our analysis also showed that treatment with letrozole slightly increased serum leptin levels without reaching the level of statistical significance. The leptin baseline levels showed a strong correlation to the body mass index 
(BMI) of the patients (rho=0.7, $\mathrm{p}=0.001$ ) as expected (Fig. 4). Furthermore, we observed a trend towards a reduction of serum levels of adiponectin during treatment with exemestane.

Some of the cytokines belonging to the TNF superfamily were found decreased during letrozole therapy while increased during exemestane treatment. These include TNF alpha, TNF Receptor Superfamily Member 8 (TNFRSF8) or sCD30, TNF Superfamily Member 13B (TNFS13B) or BAFF. The level of statistical significance was, however, only reached for sCD30/TNFRSF8 $(\mathrm{p}=0.003)$.

Progesterone receptor (PGR) status varied among patients participating in this study (Table 1). Interestingly, one member of the IL-10 cytokine family, interleukin 19 (IL-19), showed significant variations in serum levels relative to PGR status. Thus, patients with PGR negative breast cancer had significantly higher levels of IL-19 compared to patients with PGR positive breast cancer $(\mathrm{p}<0.01)$.

No significant changes in serum levels of any other adipokines were registered during treatment with aromatase inhibitors.

\section{Discussion}

While aromatase inhibitors are widely established as standard of care in all phases of ERpositive breast cancer variants in postmenopausal women, several important questions are still unanswered concerning their basic mechanisms of action in vivo. Thus, a lack of crossresistance between non-steroidal aromatase inhibitors (like letrozole) and steroidal aromatase inactivators (like exemestane) has been well-documented during treatment of metastatic breast cancer $[10,12-16,19,32]$. This phenomenon has caused the establishment of exemestane therapy, either as monotherapy or in concert with mTOR-inhibitors like everolimus, following progression on non-steroidal AIs (letrozole / anastrozole) in the recommended treatment guidelines in many countries worldwide. To explore the potential 
mechanisms behind this important clinical observation, probably based on a fundamental, although not understood difference between the two major classes of AIs, we conducted the NEOLETEXE-trial at our institution (Fig. 1). The study allows a direct head-to-head comparison of two of the most widely used aromatase disrupting agents, letrozole and exemestane. The results of a pre-planned substudy focusing on the influence of AI therapy on cytokines in general and adipokines in particular are given here.

Most interestingly, we present here evidence for a strong negative effect of exemestane therapy on serum leptin levels that is strikingly contrasted by the absence of this effect during letrozole therapy when given to the same patients in sequence (Fig. 3). This finding was not at all depending on the sequence of drugs as it could be shown in both treatment arms independent whether exemestane was given as the first of second treatment in the neoadjuvant setting (Fig. 3). While the regulation of leptin levels by steroids is still a controversial point [33], androgens have been suggested to decrease plasma leptin levels, while estrogens are believed to increase leptin levels in vivo [34-38]. Thus, one possible explanation for the observed decrease of plasma leptin levels during monotherapy with exemestane seen in our study may be due to the androgenic effects of exemestane and its major metabolite 17-hydroxy-exemestane [39]. Estrogen suppression alone did not decrease leptin levels in vivo as documented by a modest increase of leptin serum concentrations during monotherapy with the extremely potent aromatase inhibitor letrozole in our study. In contrast to the steroidal compound exemestane, letrozole belongs to the pharmacological group of triazoles and does not exert androgen effects in vivo.

Our results indicate in fact a dual mode of action of exemestane in vivo. First, exemestane is working as a classical steroidal aromatase inactivator, causing metabolism of an aromatase molecule following binding of exemestane [4]. This reaction is also called "suicide-binding" in the literature [40]. In addition, our results presented here suggest an 
additional effect on aromatase expression due to the negative effect on leptin levels. Leptin has been shown to enhance aromatase expression via AP-1 in the MCF-7 cell line [27]. As a consequence, exemestane, in addition to be a classical aromatase inactivator, probably downregulates aromatase synthesis directly by suppression of leptin effects on promoter II and I.3 of the CYP19 gene. This additional effect of exemestane on the CYP19 promoter level is not present during therapy with letrozole, according to our findings presented here and may, at least partly, explain why exemestane may cause clinical responses in breast cancer patients who experience disease progression during a non-steroidal aromatase inhibitor. Moreover, it has been shown by Catalano et al. [41] that leptin is able to induce a functional activation of ER alpha in MCF-7 cells via ERK1/ERK2 signaling. Thus, additional beneficial effects of leptin suppression by exemestane, not related to CYP19 regulation, cannot be entirely ruled out and may contribute to the reported clinical effects of exemestane following non-steroidal AIs.

Treatment with exemestane also caused a trend towards a (non-significant) suppression of serum adiponectin not observed during letrozole therapy. Adiponectin is produced by metabolically active white adipose tissue and inversely associated with adiposity. Adiponectin is believed to reduce the risk and the progression of breast cancer via its antiproliferative and possibly pro-apoptotic effects on breast cancer cells [42, 43]. No other adipokines were considerably affected by treatment of exemestane or letrozole in this trial.

Our cytokine panels allowed us also to investigate the potential effects of letrozole and exemestane on selected members of the Tumor Necrosis Factor (TNF) superfamily. While all members of the TNF superfamily, consisting of 19 ligands and 29 receptors [44], have been suggested to be involved in a variety of cellular events including proliferation, differentiation and apoptosis, the B-cell activating factor of TNF family (BAFF) has recently gained extra attention due to its major role in regulating the tumor microenvironment including induction 
of apoptosis $[45,46]$. In the present study we found sCD30/TNFRSF8 to be significantly increased during exemestane therapy $(\mathrm{p}<0.003)$ while it was suppressed by letrozole. Thus, our findings indicate distinct influences of different aromatase inhibitors on key regulators of inflammation and immunity in human breast cancer that deserve further investigation.

The patients enrolled in the NEOLETEXE-trial were typical luminal-A breast cancer patients with highly ER-positive tumors with co-expression of PGR in 31 of 39 individual cases. However, a sub-population with ER-positive/PGR-negative tumors in our trial $(\mathrm{n}=8)$ gave us the opportunity to study cytokine profiles in these two subgroups of patients. Although the patient numbers are actually small, we found significantly elevated IL-19 levels in patients with ER-positive / PGR-negative BC when compared to ER-pos./PGR-positive cases $(\mathrm{p}<0.01)$. Interleukin 19 is a cytokine belonging to the IL-10 family with multiple roles in immune regulation [47, 48]. In breast cancer, interleukin 19 seems to play an especially important role in disease progression [49]. Hsing et al. recently showed that upregulated IL19 is associated with poor clinical outcome in BC patients [50]. It is well-known for all breast cancer clinicians that loss of PGR is indicating a worse prognosis in BC patients compared to PGR positive cases in general. The precise link between PGR negativity and elevated IL-19 levels is currently unknown and will be investigated in follow-up spin-offs.

Finally, we studied the effects of neoadjuvant letrozole and exemestane on metalloproteinases (MMPs). Breast cancer cells may release metalloproteinases to degrade matrix macromolecules, allowing the invasion of tissue barriers, blood vessels and lymph channel walls [51-54]. In our study, we were able to study the effects of AI therapy on three pivotal metalloproteinases simultaneously: MMP1 (collagenase-1), MMP2 (gelatinase-A) and MMP3 (stromelysin-1). We found a trend towards a suppression of MMP3 during exemestane therapy when compared to letrozole $(\mathrm{p}<0.084)$, while the findings for MMP1 and MMP2 were not significantly different between the two AIs. Our findings are contrasting findings 
made by others in vitro, showing that letrozole may decrease MMP2 levels [55]. Thus, exemestane may, in contrast to letrozole, have additional positive treatment effects on metalloproteinase 3 by decreasing its levels in vivo as indicated here.

\section{Conclusions}

Treatment with exemestane significantly lowered serum leptin levels in breast cancer patients while letrozole did not. Our findings suggest a dual mode of action for exemestane, downregulating CYP-19 (aromatase) synthesis due to direct effects on the CYP19 gene promoter use in addition to the well-known effects as a classical aromatase inactivator. The important role of leptin in breast cancer carcinogenesis and progression may influence the choice of aromatase inhibitors based on their distinct influence on adipokines like leptin in vivo. Finally, our results suggest a potential role for exemestane, especially in obese postmenopausal women who are typically harboring elevated leptin levels. 


\section{Declarations}

\section{Ethics approval and consent to participate}

The research protocol was evaluated and approved by the Regional Ethics Committee of South-East Norway (project number 2015-84). All patients gave their written informed consent prior to participation. The biobank for the NEOLETEXE-trial was approved by the Regional Ethics Committee and located and administered at the Akershus University Hospital, Lørenskog, Norway.

\section{Consent for publication}

All patients starting treatment according to the NEOLETEXE-protocol gave their written informed consent for their clinical data and specimens to be used for teaching and scientific publications.

\section{Availability od data and materials}

All datasets used and analysed during this study are available from the corresponding author on reasonable request.

\section{Acknowledgements}

We would like to acknowledge our study nurses Christin Johansen, Marie Loeng and Annika Lorentzen who helped us to collect all blood and tissue specimens during the NEOLETEXEtrial. 


\section{Authors`contributions}

N.B. and S.B. contributed equally to the manuscript and should be considered joint first authors. N.B., S.J., V.N.K. and J.G. devised the article. N.B., S.J. and J.G. collected the data. N.B., S.J. and J.G. analysed the data and drafted the original article. T.S. was the responsible breast cancer pathologist for this publication. N.B., H.P.Ø., B.G., L.C.R., S.G. and J.G. were involved in the clinical management and treatment of the patients. N.B., S.J., T.S., H.P.Ø., S.G., B.G., L.C.R., V.N.K. and J.G. edited and contributed to the intellectual content of this original article and reviewed the article prior to submission.

\section{Competing interests}

The authors declare that they have no competing interests.

\section{Funding}

This study is an investigator-initiated study without any support from the pharmaceutical industry. The authors want to thank the administration of the South-Eastern health region of Norway for a scientific grant (no. 2017033) allowing this work to be performed as a part of the $\mathrm{PhD}$ thesis of N.B. 
Figures (headlines and legends)

Figure 1. Study design - the NEOLETEXE study

Figure 2: Spearman correlations between baseline serum levels of adipokines

Spearman correlations between serum levels of 12 adipokines $(n=39$, timepoint: baseline $)$ are shown by correlation dot plots, as well as by correlation coefficient values (rho) with significance (p) values. Significant $p$ values are highlighted bold.

Figure 3: Influence of treatment with letrozole and exemestane on serum adipokine levels

Bar plot representing median log serum levels difference (y-axis) of 12 adipokines (x-axis) in breast cancer patients $(n=39)$, relative to neoadjuvant drug type and therapy time-point (color categories). Error bars represent 95\% confidence interval.

Figure 4: Correlation between plasma leptin levels (baseline) and body mass index (BMI)

Dot plot to illustrate Spearman correlation between BMI (x-axis) and serum levels of leptin (y-axis) in breast cancer patients. 


\section{References}

1. Geisler J, Detre S, Berntsen H, Ottestad L, Lindtjorn B, Dowsett M, Lønning PE: Influence of neoadjuvant anastrozole (Arimidex) on intratumoral estrogen levels and proliferation markers in patients with locally advanced breast cancer. Clin Cancer Res 2001, 7(5):1230-1236.

2. Geisler J, Haynes B, Anker G, Dowsett M, Lønning PE: Influence of letrozole and anastrozole on total body aromatization and plasma estrogen levels in postmenopausal breast cancer patients evaluated in a randomized, cross-over study. J Clin Oncol 2002, 20(3):751-757.

3. Geisler J, Helle H, Ekse D, Duong NK, Evans DB, Nordbo Y, Aas T, Lønning PE: Letrozole is superior to anastrozole in suppressing breast cancer tissue and plasma estrogen levels. Clin Cancer Res 2008, 14(19):6330-6335.

4. Geisler J, King N, Anker G, Ornati G, Di Salle E, Lønning PE, Dowsett M: In vivo inhibition of aromatization by exemestane, a novel irreversible aromatase inhibitor, in postmenopausal breast cancer patients. Clin Cancer Res 1998, 4(9):2089-2093.

5. Geisler J, King N, Dowsett M, Ottestad L, Lundgren S, Walton P, Kormeset PO, Lønning PE: Influence of anastrozole (Arimidex), a selective, non-steroidal aromatase inhibitor, on in vivo aromatisation and plasma oestrogen levels in postmenopausal women with breast cancer. Br J Cancer 1996, 74(8):1286-1291.

6. Geisler J, Lønning PE: Aromatase inhibition: translation into a successful therapeutic approach. Clin Cancer Res 2005, 11(8):2809-2821.

7. Cole PA, Robinson CH: Mechanism and inhibition of cytochrome P-450 aromatase. J Med Chem 1990, 33(11):2933-2942.

8. di Salle E, Ornati G, Giudici D, Lassus M, Evans TR, Coombes RC: Exemestane (FCE 24304), a new steroidal aromatase inhibitor. J Steroid Biochem Mol Biol 1992, 43(1-3):137-143.

9. Lønning PE: Aromatase inhibitors in breast cancer. Endocr Relat Cancer 2004, 11(2):179-189.

10. Lønning PE, Bajetta E, Murray R, Tubiana-Hulin M, Eisenberg PD, Mickiewicz E, Celio L, Pitt P, Mita M, Aaronson NK et al: Activity of exemestane in metastatic breast cancer after failure of nonsteroidal aromatase inhibitors: a phase II trial. J Clin Oncol 2000, 18(11):2234-2244.

11. Van Asten K, Neven P, Lintermans A, Wildiers H, Paridaens R: Aromatase inhibitors in the breast cancer clinic: focus on exemestane. Endocr Relat Cancer 2014, 21(1):R31-49.

12. Steele N, Zekri J, Coleman R, Leonard R, Dunn K, Bowman A, Manifold I, Kunkler I, Purohit O, Cameron D: Exemestane in metastatic breast cancer: effective therapy after third-generation non-steroidal aromatase inhibitor failure. Breast 2006, 15(3):430-436.

13. Gennatas C, Michalaki V, Carvounis E, Psychogios J, Poulakaki N, Katsiamis G, Voros D, Kouloulias V, Mouratidou D, Tsavaris N: Third-line hormonal treatment with exemestane in postmenopausal patients with advanced breast cancer progressing on letrozole or anastrozole. A phase II trial conducted by the Hellenic Group of Oncology (HELGO). Tumori 2006, 92(1):13-17.

14. Bertelli G, Garrone O, Merlano M, Occelli M, Bertolotti L, Castiglione F, Pepi F, Fusco O, Del Mastro L, Leonard RC: Sequential treatment with exemestane and nonsteroidal aromatase inhibitors in advanced breast cancer. Oncology 2005, 69(6):471477. 
15. Chin YS, Beresford MJ, Ravichandran D, Makris A: Exemestane after non-steroidal aromatase inhibitors for post-menopausal women with advanced breast cancer. Breast 2007, 16(4):436-439.

16. Carlini P, Michelotti A, Ferretti G, Ricci S, Giannarelli D, Pellegrini M, Cresti N, Di Cosimo S, Bria E, Papaldo P et al: Clinical evaluation of the use of exemestane as further hormonal therapy after nonsteroidal aromatase inhibitors in postmenopausal metastatic breast cancer patients. Cancer Invest 2007, 25(2):102-105.

17. Geisler J: Differences between the non-steroidal aromatase inhibitors anastrozole and letrozole--of clinical importance? Br J Cancer 2011, 104(7):1059-1066.

18. Freedman OC, Amir E, Hanna W, Kahn H, O'Malley F, Dranitsaris G, Cole DE, Verma S, Folkerd E, Dowsett $\mathrm{M}$ et al: A randomized trial exploring the biomarker effects of neoadjuvant sequential treatment with exemestane and anastrozole in postmenopausal women with hormone receptor-positive breast cancer. Breast Cancer Res Treat 2010, 119(1):155-161.

19. Lønning PE: Lack of complete cross-resistance between different aromatase inhibitors; a real finding in search for an explanation? Eur J Cancer 2009, 45(4):527535.

20. Bahrami N, Sauer T, Engebretsen S, Aljabri B, Bemanian V, Lindstrom J, Luders T, Kristensen V, Lorentzen A, Loeng $M$ et al: The NEOLETEXE trial: a neoadjuvant cross-over study exploring the lack of cross resistance between aromatase inhibitors. Future Oncol 2019, 15(32):3675-3682.

21. Howe LR, Subbaramaiah K, Hudis CA, Dannenberg AJ: Molecular pathways: adipose inflammation as a mediator of obesity-associated cancer. Clin Cancer Res 2013, 19(22):6074-6083.

22. Iyengar NM, Brown KA, Zhou XK, Gucalp A, Subbaramaiah K, Giri DD, Zahid H, Bhardwaj P, Wendel NK, Falcone DJ et al: Metabolic Obesity, Adipose Inflammation and Elevated Breast Aromatase in Women with Normal Body Mass Index. Cancer Prev Res (Phila) 2017, 10(4):235-243.

23. Cirillo D, Rachiglio AM, la Montagna R, Giordano A, Normanno N: Leptin signaling in breast cancer: an overview. J Cell Biochem 2008, 105(4):956-964.

24. Halaas JL, Gajiwala KS, Maffei M, Cohen SL, Chait BT, Rabinowitz D, Lallone RL, Burley SK, Friedman JM: Weight-reducing effects of the plasma protein encoded by the obese gene. Science 1995, 269(5223):543-546.

25. Pelleymounter MA, Cullen MJ, Baker MB, Hecht R, Winters D, Boone T, Collins F: Effects of the obese gene product on body weight regulation in ob/ob mice. Science 1995, 269(5223):540-543.

26. Campfield LA, Smith FJ, Guisez Y, Devos R, Burn P: Recombinant mouse OB protein: evidence for a peripheral signal linking adiposity and central neural networks. Science 1995, 269(5223):546-549.

27. Catalano S, Marsico S, Giordano C, Mauro L, Rizza P, Panno ML, Ando S: Leptin enhances, via AP-1, expression of aromatase in the MCF-7 cell line. J Biol Chem 2003, 278(31):28668-28676.

28. Tessitore L, Vizio B, Pesola D, Cecchini F, Mussa A, Argiles JM, Benedetto C: Adipocyte expression and circulating levels of leptin increase in both gynaecological and breast cancer patients. Int J Oncol 2004, 24(6):1529-1535.

29. Paolisso G, Rizzo MR, Mone CM, Tagliamonte MR, Gambardella A, Riondino M, Carella C, Varricchio M, D'Onofrio F: Plasma sex hormones are significantly associated with plasma leptin concentration in healthy subjects. Clin Endocrinol (Oxf) 1998, 48(3):291-297. 
30. Tessitore L, Vizio B, Jenkins O, De Stefano I, Ritossa C, Argiles JM, Benedetto C, Mussa A: Leptin expression in colorectal and breast cancer patients. Int J Mol Med 2000, 5(4):421-426.

31. Geisler J, Haynes B, Ekse D, Dowsett M, Lønning PE: Total body aromatization in postmenopausal breast cancer patients is strongly correlated to plasma leptin levels. J Steroid Biochem Mol Biol 2007, 104(1-2):27-34.

32. Iaffaioli RV, Formato R, Tortoriello A, Del Prete S, Caraglia M, Pappagallo G, Pisano A, Gebbia V, Fanelli F, Ianniello G et al: Phase II study of sequential hormonal therapy with anastrozole/exemestane in advanced and metastatic breast cancer. Br J Cancer 2005, 92(9):1621-1625.

33. Newman G, Gonzalez-Perez RR: Leptin-cytokine crosstalk in breast cancer. Mol Cell Endocrinol 2014, 382(1):570-582.

34. Shimizu H, Shimomura Y, Nakanishi Y, Futawatari T, Ohtani K, Sato N, Mori M: Estrogen increases in vivo leptin production in rats and human subjects. J Endocrinol 1997, 154(2):285-292.

35. Luukkaa V, Pesonen U, Huhtaniemi I, Lehtonen A, Tilvis R, Tuomilehto J, Koulu M, Huupponen R: Inverse correlation between serum testosterone and leptin in men. $\mathbf{J}$ Clin Endocrinol Metab 1998, 83(9):3243-3246.

36. Machinal F, Dieudonne MN, Leneveu MC, Pecquery R, Giudicelli Y: In vivo and in vitro ob gene expression and leptin secretion in rat adipocytes: evidence for a regional specific regulation by sex steroid hormones. Endocrinology 1999, 140(4):1567-1574.

37. Machinal-Quelin F, Dieudonne MN, Pecquery R, Leneveu MC, Giudicelli Y: Direct in vitro effects of androgens and estrogens on ob gene expression and leptin secretion in human adipose tissue. Endocrine 2002, 18(2):179-184.

38. Wabitsch M, Blum WF, Muche R, Braun M, Hube F, Rascher W, Heinze E, Teller W, Hauner H: Contribution of androgens to the gender difference in leptin production in obese children and adolescents. J Clin Invest 1997, 100(4):808-813.

39. Ariazi EA, Leitao A, Oprea TI, Chen B, Louis T, Bertucci AM, Sharma CG, Gill SD, Kim HR, Shupp HA et al: Exemestane's 17-hydroxylated metabolite exerts biological effects as an androgen. Mol Cancer Ther 2007, 6(11):2817-2827.

40. Hong Y, Yu B, Sherman M, Yuan YC, Zhou D, Chen S: Molecular basis for the aromatization reaction and exemestane-mediated irreversible inhibition of human aromatase. Mol Endocrinol 2007, 21(2):401-414.

41. Catalano S, Mauro L, Marsico S, Giordano C, Rizza P, Rago V, Montanaro D, Maggiolini M, Panno ML, Ando S: Leptin induces, via ERK1/ERK2 signal, functional activation of estrogen receptor alpha in MCF-7 cells. J Biol Chem 2004, 279(19):19908-19915.

42. Ollberding NJ, Kim Y, Shvetsov YB, Wilkens LR, Franke AA, Cooney RV, Maskarinec G, Hernandez BY, Henderson BE, Le Marchand L et al: Prediagnostic leptin, adiponectin, $\mathrm{C}$-reactive protein, and the risk of postmenopausal breast cancer. Cancer Prev Res (Phila) 2013, 6(3):188-195.

43. Jarde T, Perrier S, Vasson MP, Caldefie-Chezet F: Molecular mechanisms of leptin and adiponectin in breast cancer. Eur J Cancer 2011, 47(1):33-43.

44. Bodmer JL, Schneider P, Tschopp J: The molecular architecture of the TNF superfamily. Trends Biochem Sci 2002, 27(1):19-26.

45. Mackay F, Ambrose C: The TNF family members BAFF and APRIL: the growing complexity. Cytokine Growth Factor Rev 2003, 14(3-4):311-324.

46. Pelekanou V, Kampa M, Kafousi M, Darivianaki K, Sanidas E, Tsiftsis DD, Stathopoulos EN, Tsapis A, Castanas E: Expression of TNF-superfamily members 
BAFF and APRIL in breast cancer: immunohistochemical study in 52 invasive ductal breast carcinomas. BMC Cancer 2008, 8:76.

47. Chang C, Magracheva E, Kozlov S, Fong S, Tobin G, Kotenko S, Wlodawer A, Zdanov A: Crystal structure of interleukin-19 defines a new subfamily of helical cytokines. J Biol Chem 2003, 278(5):3308-3313.

48. Gallagher G: Interleukin-19: multiple roles in immune regulation and disease. Cytokine Growth Factor Rev 2010, 21(5):345-352.

49. Chen YY, Li CF, Yeh CH, Chang MS, Hsing CH: Interleukin-19 in breast cancer. Clin Dev Immunol 2013, 2013:294320.

50. Hsing $\mathrm{CH}$, Cheng $\mathrm{HC}$, Hsu YH, Chan $\mathrm{CH}$, Yeh $\mathrm{CH}$, Li CF, Chang MS: Upregulated IL-19 in breast cancer promotes tumor progression and affects clinical outcome. Clin Cancer Res 2012, 18(3):713-725.

51. Bagnoli F, Oliveira VM, Silva MA, Taromaru GC, Rinaldi JF, Aoki T: The interaction between aromatase, metalloproteinase 2,9 and CD44 in breast cancer. Rev Assoc Med Bras (1992) 2010, 56(4):472-477.

52. Martins LM, de Melo Escorcio Dourado CS, Campos-Verdes LM, Sampaio FA, Revoredo CMS, Costa-Silva DR, da Conceicao Barros-Oliveira M, de Jesus Nery Junior E, do Rego-Medeiros LM, Gebrim LH et al: Expression of matrix metalloproteinase 2 and 9 in breast cancer and breast fibroadenoma: a randomized, double-blind study. Oncotarget 2019, 10(64):6879-6884.

53. Pelekanou V, Villarroel-Espindola F, Schalper KA, Pusztai L, Rimm DL: CD68, CD163, and matrix metalloproteinase 9 (MMP-9) co-localization in breast tumor microenvironment predicts survival differently in ER-positive and -negative cancers. Breast Cancer Res 2018, 20(1):154.

54. Tauro M, Lynch CC: Cutting to the Chase: How Matrix Metalloproteinase-2 Activity Controls Breast-Cancer-to-Bone Metastasis. Cancers (Basel) 2018, 10(6).

55. Mitropoulou TN, Tzanakakis GN, Kletsas D, Kalofonos HP, Karamanos NK: Letrozole as a potent inhibitor of cell proliferation and expression of metalloproteinases (MMP-2 and MMP-9) by human epithelial breast cancer cells. Int J Cancer 2003, 104(2):155-160. 
Figures
Baseline*
8 Weeks $^{*}$
16 Weeks $^{*}$
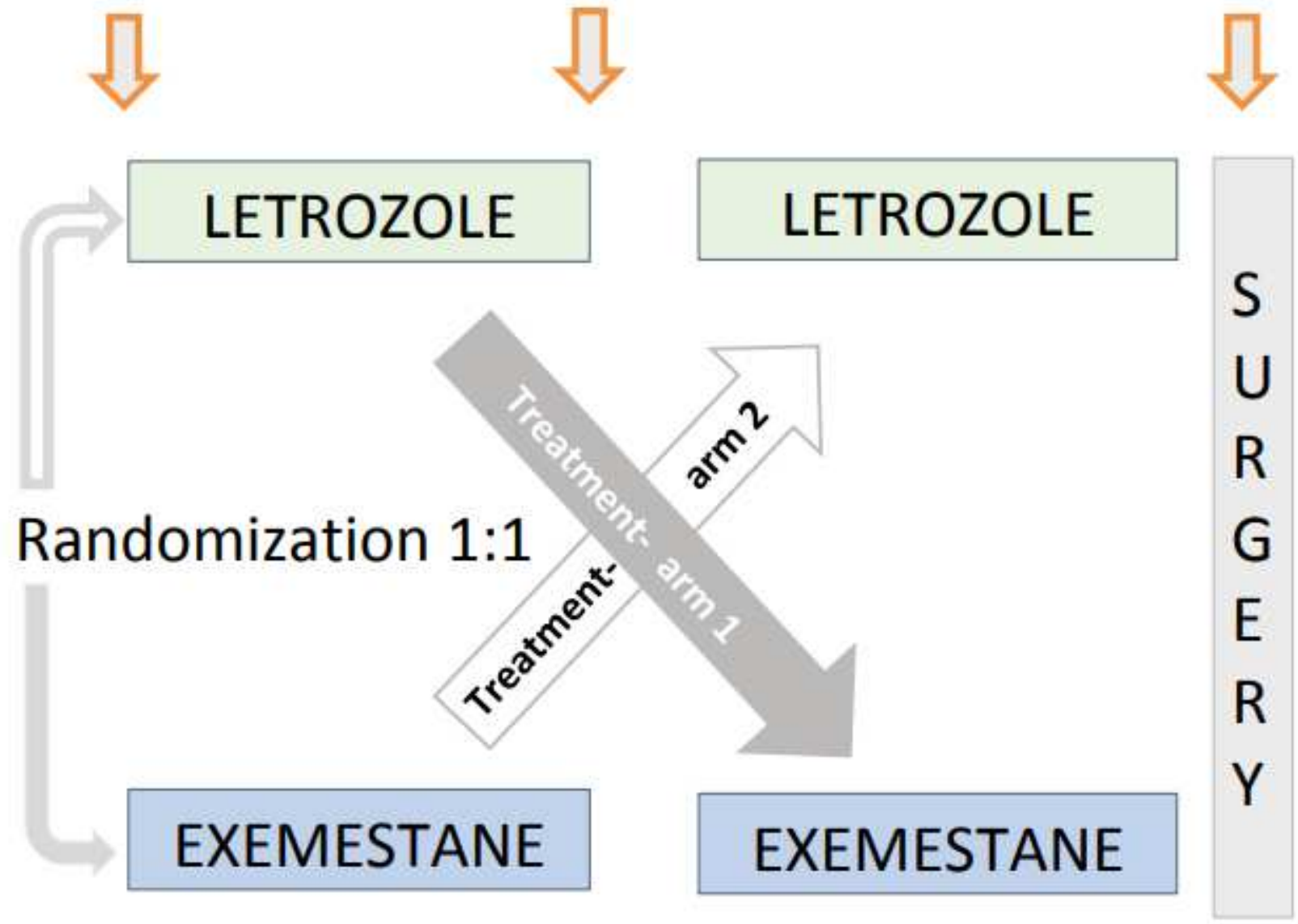

*Blood/ serum samples/biopsies/tumor evaluation

Figure 1

Study design - the NEOLETEXE study 


\begin{tabular}{|c|c|c|c|c|c|c|c|c|c|c|c|c|c|}
\hline & $\begin{array}{l}\frac{0}{0} \\
\frac{0}{0} \\
\frac{0}{0}\end{array}$ & 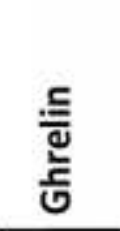 & 은 & 䘚 & 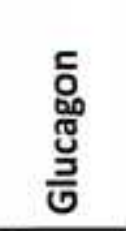 & $\begin{array}{l}\text { 들 } \\
\text { 들 }\end{array}$ & 듬 & $\begin{array}{l}\text { 등 } \\
\text { 등 } \\
\text { 음 }\end{array}$ & $\frac{7}{\frac{1}{\alpha}}$ & 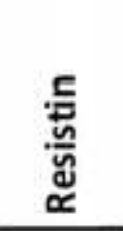 & $\frac{\text { 章 }}{\frac{\pi}{5}}$ & $\stackrel{\varphi}{=}$ & \\
\hline \multirow{2}{*}{ C-peptide } & 1 & $392 *$ & *,408** & \%,488** & , 338** & 870** & $4,466^{* *}$ & $274^{* 1}$ & & & 0,193 & $184^{*}$ & rho \\
\hline & otill & 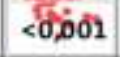 & $\leq 0,001$ & 8,001 & $<0,001$ & $<0,001$ & 20,001 & 0,003 & 0,05 & $-0,921$ & 8268 & 6,047 & p \\
\hline Ghrelin & $\begin{array}{l}-392^{* *} \\
<0,001\end{array}$ & & 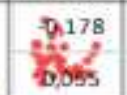 & $\frac{-2,181}{6 \times 0}$ & $\begin{array}{c}.225^{*} \\
0,015\end{array}$ & $\frac{275^{*}=}{6,003}$ & $\frac{\pi, 152}{0.0705}$ & . 0,135 & $\frac{0,095}{\cdot 0, \frac{8}{8}}$ & $\begin{array}{l}, 208^{*} \\
0,025\end{array}$ & $\frac{209 *}{0,024}$ & 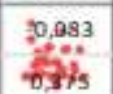 & rho \\
\hline GIP & $\begin{array}{c}408^{* *} \\
0 \% 001\end{array}$ & $\frac{0478}{20065}$ & 1) & $\frac{644^{* *}}{<0,001}$ & $\begin{array}{l}, 553^{* *} \\
<0,001\end{array}$ & $\begin{array}{l}430 * * \\
<0,001\end{array}$ & ang & $\begin{array}{l}, 2611^{* *} \\
0,005\end{array}$ & $\begin{array}{l}-0,203 \\
-0,28\end{array}$ & $\begin{array}{r}0,092 \\
\therefore ; 0,382\end{array}$ & $\frac{587^{* *}}{<0 ; 001}$ & 259** & * rho \\
\hline GLP-1 & $488 * *$ & $\frac{7}{4}$ & $644^{* *}$ & $=1 \mathrm{f}$. & $718^{* *}$ & $400 * *$ & $\begin{array}{l}-0.042 \\
-72=5\end{array}$ & $.277^{*}=$ & 0,049 & $-0,117$. & $530^{* *}$ & $587^{* *}$ & * rho \\
\hline \multirow[b]{2}{*}{ Glucagon } & $338 * *$ & & $553 * *$ & $* 718 * *$ & & $400 * *$ & & & & & & & rho \\
\hline & $<0,001$ & , & - 0,001 & $<0,001$ & adilling & <0,001 & $\begin{array}{l}9.7 \% \\
0.948\end{array}$ & $\begin{array}{r}2,21,5 \\
0,019\end{array}$ & $0,0,429$ & $\therefore=$ & $<0,001$ & $<0 ; 001$ & p \\
\hline \multirow[t]{2}{*}{ Insulin } & $870^{* *}$ &., $275 *$ & $*, 43 g^{* *}$ &, 4 & *,402:* & &, $582^{* *}$ &,$- 233^{*}$ & $233^{*}$ & & 0.227 & $\operatorname{pog} 2$ & rho \\
\hline & 0,001 & 0,003 & $<0,001$ & $<0,001$ & 40,001 & dillhm & <6,001 & 0,012 & 0,011 & $-\infty, n \frac{3}{3}$ & Atis & Dañ & p \\
\hline \multirow[t]{2}{*}{ Leptin } & $\begin{array}{l}466 * * \\
<0,001\end{array}$ & 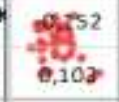 & $\begin{array}{l}3057 \\
307 \\
0143\end{array}$ & $\frac{0.042}{0.455}$ & $\begin{array}{l}9096 \\
099 \\
09948\end{array}$ & $\frac{582 * *}{50,001}$ & 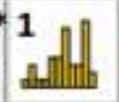 & $\cdot \frac{-0,166}{0,074}$ & $\begin{array}{r}0,198 \\
0,0,056 \\
\end{array}$ & $\begin{array}{r}.0,758 \\
-0296\end{array}$ & 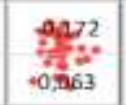 & $\frac{9632}{7}$ & $\begin{array}{l}\text { rho } \\
\text { p }\end{array}$ \\
\hline &,$- 274^{*}$ & 1 opass & $-261 * *$ & $\cdot, 277^{k x}$ & t-;217** & $4233^{*}$ & > =ases & 1 & 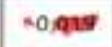 & $=00007$ & Dotas &, $380^{*}$ & rho \\
\hline diponectin & 0,003 & 0,148 & 0,005 & 0,002 & 0,019 & 0,012 & 0.974 & -1 & 0,842 & 0,213 & 0,157 & $<0,001$ & p \\
\hline \multirow{2}{*}{ PAl-1 } & $-6,99$ & 9095 & sphas & qxias & 喁有 & $233^{\circ}$ & ings: & $-0,014$ & $1 \mathrm{fth}$ & "qle? & $\operatorname{eg}_{3}$ & 040 & rho \\
\hline & 0,053 & 0,31 & $-0,27$ & 0.599 & 0,429 & 0,011 & $\cdot 0,056$ & 0.842 & . Alllh & $\cdot 0,113$ & 40,051 & 0884 & $\mathbf{p}$ \\
\hline \multirow{2}{*}{ Resistin } & $=2,909$ & $208 *$ & 20.983 & Ay? & ogre & tons. & 9139 & $0,14 \mathrm{~g}$ & 0,197 & 1 & 2807. &, $350^{*}$ & rho \\
\hline & Q921 & 0,025 & 0382 & 0.211 & $0 \% 895$ & 20,213 & $.0,136$ & 0,119 & 0,113 & $=\|\|_{\mathrm{b}}$ & .0047 & $<0,001$ & p \\
\hline \multirow{2}{*}{ Visfatin } & .1.103 & $209^{*}$ &, $587^{* *}$ & $*, 530 * *$ & k,708** & 10127. & $-0^{2} 72$ & $.0,13$ & $0,1 b_{3}$ & 8067 & $1 \mathrm{~h}$ & $335^{* *}$ & * rho \\
\hline & 0.267 & 0,024 & $<0,001$ & $<0,001$ & $<0,001$ & 8,171 & 0,685 & 0,157 & 0,051 & .047 & Aillm. & $<0 ; 001$ & p \\
\hline IL-6 & $\frac{.184^{*}}{0,047}$ & $\frac{n, 8,3}{b, 3 \neq 5}$ & $\begin{array}{l}259 * * \\
0,005\end{array}$ & $\frac{.587^{* *}}{<0,001}$ & $=\frac{413 t^{*}}{<0,001}$ & $\frac{9.972}{8,442^{72}}$ & $\frac{09032}{2}$ & $\begin{array}{c}380^{* * 1} \\
<0,001\end{array}$ & $\frac{0.019}{0.84}$ & $\begin{array}{l}380^{*} \\
<0,001\end{array}$ & $\begin{array}{l}335^{* *} \\
<0,001\end{array}$ & 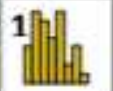 & $\begin{array}{l}\text { rho } \\
\text { p }\end{array}$ \\
\hline
\end{tabular}

Figure 2

Spearman correlations between baseline serum levels of adipokines Spearman correlations between serum levels of 12 adipokines ( $n=39$, timepoint: baseline) are shown by correlation dot plots, as well as by correlation coefficient values (rho) with significance $(\mathrm{p})$ values. Significant $\mathrm{p}$ values are highlighted bold. 




Figure 3

Influence of treatment with letrozole and exemestane on serum adipokine levels Bar plot representing median log serum levels difference (y-axis) of 12 adipokines (x-axis) in breast cancer patients $(n=39)$, relative to neoadjuvant drug type and therapy time-point (color categories). Error bars represent $95 \%$ confidence interval. 


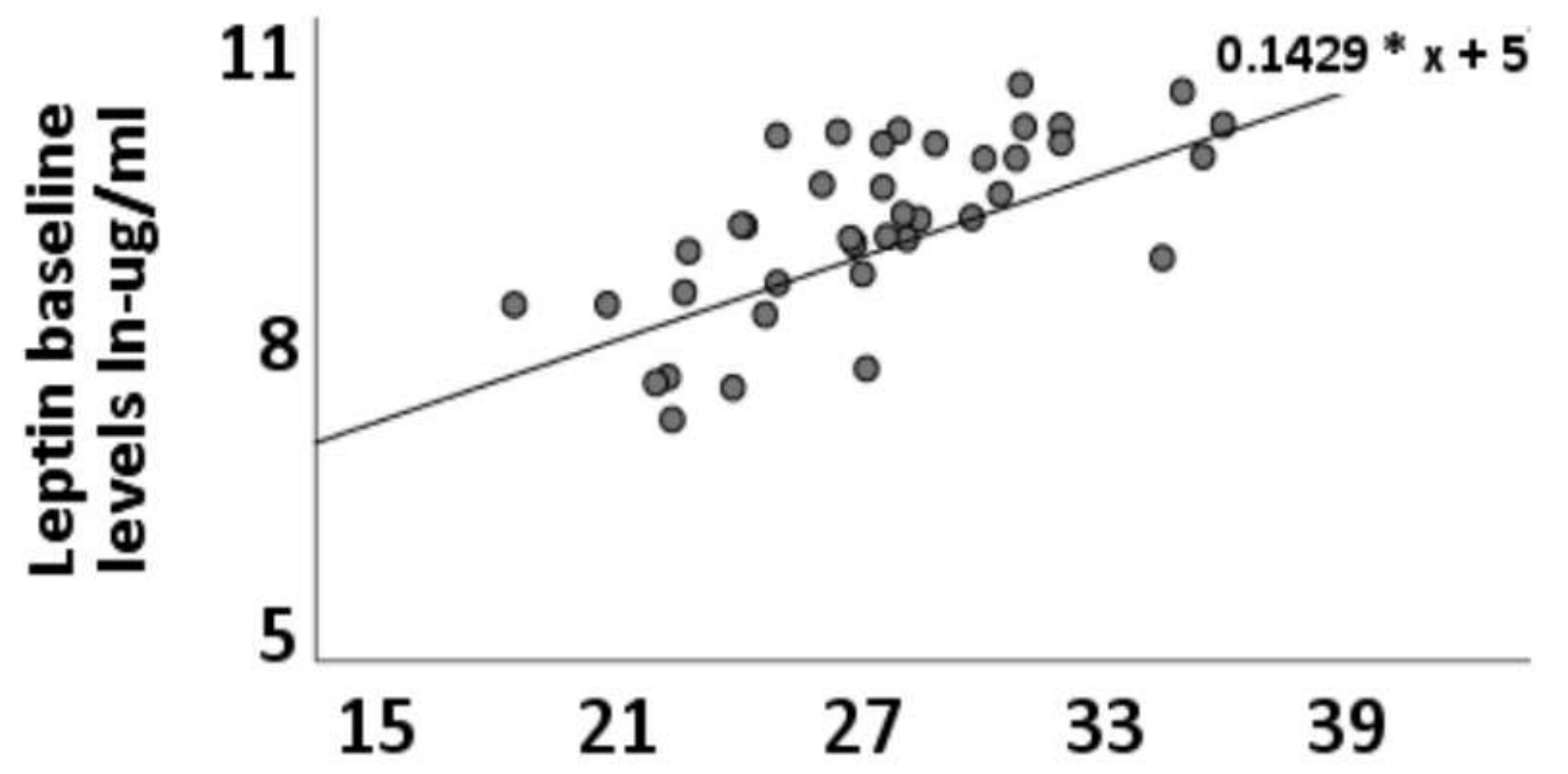

\section{Spearman corr rho $=0.727 \mathrm{P}<0.001$ No. of patients $=39$

Figure 4

Correlation between plasma leptin levels (baseline) and body mass index (BMI) Dot plot to illustrate Spearman correlation between BMI (x-axis) and serum levels of leptin (y-axis) in breast cancer patients.

\section{Supplementary Files}

This is a list of supplementary files associated with this preprint. Click to download.

- Table1BCR09.08.20.pdf

- Table2BCR09.08.20.pdf 